\title{
O Ensino de Permacultura no Brasil: o papel dos Cursos de Design em Permacultura (PDCs) e as contribuições da Educação Ambiental Crítica
}

\section{Permaculture Teaching in Brazil: the role of Permaculture Design Courses (PDCs) and the contributions of Critical Environmental Education}

\author{
André Santachiara Fossaluza' \\ Marília Freitas de Campos Tozoni-Reis² \\ 'Universidade Estadual Paulista (UNESP), Faculdade de Ciências, Programa de Pós-Graduação em Educação para a \\ Ciência, Bauru, SP. Brasil. Autor correspondente: fossaluza.andre@gmail.com \\ ${ }^{2}$ Universidade Estadual Paulista (UNESP), Instituto de Biociências, Departamento de Educação, Botucatu, SP, Brasil.
}

Resumo: A permacultura é um movimento que busca planejar, criar e manter assentamentos humanos sustentáveis, sendo difundida, principalmente, pelos Cursos de Design em Permacultura (PDCs). Neste trabalho, mapeamos esses cursos no Brasil e discutimos o ensino de permacultura e seu diálogo com a educação ambiental crítica, por meio dos resultados obtidos após a aplicação de um questionário. A partir das respostas de educadores/as de PDCs, analisamos esses cursos quanto aos seus objetivos, valores de inscrição e perfil dos/as educadores/as. Encontramos 38 grupos que oferecem PDCs e 210 educadores/as atuantes no Brasil, cujos dados permitiram compreender seu perfil quanto a gênero, à raça/etnia e à renda (classe social), assim como discutir os propósitos desses cursos e a popularização da permacultura. As análises nos permitem dizer que o ensino de permacultura no Brasil se configura como um campo de disputa, com ações de caráter contraditório e heterogêneo.

Palavras-chave: Permacultura; Agricultura socioambiental; Educação ambiental; Sociedade sustentável.

Abstract: Permaculture is a movement that seeks to plan, create and maintain sustainable human settlements and that has been especially promoted by Permaculture Design Courses (PDCs). In this article, following the analysis of a questionnaire, we present the distribution of these courses in Brazil and discuss the teaching of permaculture and its interactions with critical environmental education. Based on the answers provided by PDC educators, we analyze the courses with regard to content, fees, and the profile of educators. We have found 38 groups that offer PDCs and 210 PDC educators in Brazil, and the data have enabled us to analyze the profile of PDC educators regarding gender, race/ethnicity and income (social class). We have also been able to discuss the objectives in the PDCs, and the popularization of permaculture. The analysis indicates that permaculture teaching in Brazil is a field of dispute with heterogeneous and contradictory actions.

Keywords: Permaculture; Environmental education; Socio-environmental agriculture; Sustainable society.

Recebido em: 03/03/2020

Aprovado em: 09/06/2020 


\section{Permacultura e Educação Ambiental}

Vivemos numa sociedade ambientalmente e socialmente desigual e desequilibrada. Paralelamente ao crescente volume de estudos que indicam níveis alarmantes de emissão de gases do efeito estufa, poluição dos oceanos, desmatamentos e incêndios florestais de imensas proporções, convivemos com o aumento da desigualdade social e do número de pessoas em situação de rua, maior concentração de riquezas nas mãos de poucas pessoas, índices maiores de desemprego e de desocupação, perda de direitos sociais, previdenciários e trabalhistas, crescentes casos de violência física e moral contra pessoas negras, indígenas, LGBTQI+, mulheres etc.

Aliado a discursos conservadores e, muitas vezes, sem nenhuma base de dados e análises cientificamente confiáveis, esse contexto nos mostra um crescente panorama de crise, acentuada pela pandemia global da COVID-19.

É importante, porém, relembrarmos que o estado de crise é inerente à própria sociedade capitalista, com a exploração de uma pessoa pela outra, a alienação do trabalho, a acumulação de capital pelos detentores dos meios de produção, entre outras características. A história nos mostra momentos de apaziguamento ou aprofundamento dessa crise diríamos que, certamente, vivemos atualmente um dramático período de aprofundamento.

Muitos foram e são os movimentos propondo alternativas para esse modo de produção. As contradições evidentes na sociedade mostram que a tecnologia e a informação não são capazes, por si só, de fornecer os subsídios para a construção de "[...] sociedades socialmente justas e ecologicamente equilibradas" (TRATADO..., 2014, p. 85) que nos tragam felicidade: é preciso superar a visão positivista e cartesiana da ciência e do conhecimento como grande salvação da humanidade, pois, ao contrário do que ela defende, os conhecimentos científicos e técnicos não têm sido suficientes para alterar tal relação, mesmo ao assumirmos que nunca se conheceu tanto o funcionamento dos processos naturais e artificiais como hoje (TOZONIREIS, 2007). Faz-se necessária uma abordagem mais crítica diante desse modo de produção e da forma como se dá a relação entre humanidade e natureza.

Nesse contexto, a educação ambiental, em sua vertente crítica, apresenta elementos que contribuem para a criação, tanto no plano ideal quanto no material, de novas realidades sociais e ambientais.

Atualmente, diversas pessoas e instituições protagonizam as ações em educação ambiental, as quais, por vezes cooperam, por outras, batalham entre si para resolverem problemáticas ambientais a partir da educação. Simultaneamente, o campo de pesquisa em educação ambiental tem se desenvolvido e amadurecido, a ponto de constatarmos que não há uma única educação ambiental, mas diferentes vertentes que apresentam distintas concepções de mundo, bases teóricas, objetivos e metodologias (SAUVÉ, 2005; SCHILLINGTREIN, 2012).

Nesse sentido, destacamos as contribuições de Layrargues e Lima (2014) ao campo da educação ambiental ao discutirem três principais macrotendências político-pedagógicas da educação ambiental brasileira. Segundo os autores, as ações podem ser mais alinhadas com as tendências conservacionistas, pragmáticas ou críticas: "[...] da mesma maneira que existem diferentes concepções de natureza, meio ambiente, sociedade e educação, também existem diferentes concepções de Educação Ambiental" (LAYRARGUES; LIMA, 2014, p. 27). 
Enquanto as macrotendências conservacionistas e pragmáticas têm caráter reformista e de minimização de impactos, as vertentes críticas de educação ambiental vão ao cerne dessa crise societária: não faz sentido "[...] lutar por outra cultura na relação entre humano e natureza, sem também lutar por uma nova sociedade" (LAYRARGUES; LIMA, 2014, p. 29):

\begin{abstract}
Essa opção pedagógica se nutriu do pensamento Freireano, dos princípios da Educação Popular, da Teoria Crítica, da Ecologia Política e de autores marxistas e neomarxistas que pregavam a necessidade de incluir no debate ambiental a compreensão dos mecanismos da reprodução social, de que a relação entre o ser humano e a natureza é mediada por relações socioculturais e de classes historicamente construídas. Trazem uma abordagem pedagógica que problematiza os contextos societários em sua interface com a natureza. Por essa perspectiva não era possível conceber os problemas ambientais dissociados dos conflitos sociais; afinal, a crise ambiental não expressava problemas da natureza, mas problemas que se manifestavam na natureza. As causas constituintes destes problemas tinham origem nas relações sociais, nos modelos de sociedade e de desenvolvimento prevalecentes.
\end{abstract}

Isso não significa dizer que ações voltadas à conservação de uma espécie ou à alteração de comportamentos individuais sejam inválidas, mas que não são suficientes quando almejamos uma real transição para sociedades sustentáveis.

Por essa perspectiva crítica chegamos à permacultura. Assim como a educação ambiental, a permacultura é um movimento que se iniciou e se expandiu num contexto de intensificação da crise socioambiental nas décadas de 1960 e 1970, período histórico de intensa mobilização mundial em questões ambientais, sociais e políticas (FERGUSON; LOVELL, 2014).

Tal como a agroecologia e as agriculturas orgânica, natural e biodinâmica, por exemplo, a permacultura tem como foco inicial de crítica a agricultura convencional, com propostas e ações criadas em resposta à chamada Revolução Verde (RIBEIRO et al., 2017). Apesar de cada um desses movimentos ter surgido em diferentes contextos, eles têm em comum a busca por relações baseadas na observação do funcionamento dos sistemas naturais, dos processos ecológicos de cooperação e em outras formas de organização comunitária.

A permacultura surge na Austrália após um trabalho acadêmico desenvolvido por David Holmgren e Bill Mollison. Inicialmente, o conceito foi criado pela junção dos termos agriculture e permanent (agricultura permanente), pois apresentava as bases para um sistema de cultivo de alimentos que tinha como pilar a utilização de espécies perenes ao invés das predominantes plantas sazonais, geralmente anuais, existentes nos sistemas agrícolas, dialogando com as abordagens de Joseph Russel Smith em 1929, em seu livro Tree crops: a permanent agriculture e de Mokiti Okada, com a Agricultura Natural (RIBEIRO et al., 2017).

Ao longo do tempo, a permacultura passou a incorporar novos elementos, sendo compreendida atualmente como "cultura permanente" ou "cultura da permanência" (FERGUSON; LOVELL, 2014). Venkat (2017) explica que a permacultura é um modo de vida alternativo, que tem como base uma relação de cooperação e não-exploração da biosfera. Em outras palavras, podemos definir a permacultura como:

Design consciente e a manutenção de ecossistemas agriculturalmente produtivos que tenham a diversidade, estabilidade e resiliência de ecossistemas naturais. Ela é a integração harmoniosa entre a paisagem e as pessoas, providenciando alimento, 
energia, abrigo e outras necessidades materiais e não-materiais de forma sustentável. Sem uma agricultura permanente, não há possibilidade de uma ordem social estável estável. O design Permacultural é um sistema de união de componentes conceituais, materiais e estratégicos num padrão que funciona para beneficiar a vida em todas as suas formas (MOLLISON, 2009, p. ix, tradução nossa).

De forma sintética, podemos dizer que três pilares a sustentam:

1. Ecologia: o estudo do funcionamento de sistemas naturais permite apreender conceitos que sustentam o planejamento e a manutenção de assentamentos humanos sustentáveis.

2. Ética: segundo Holmgren (2002), a ética da permacultura foi desenhada a partir de pesquisas sobre os preceitos éticos de comunidades tradicionais, como comunidades religiosas antigas e grupos cooperativos, argumentando que eles são comuns a todos os povos indígenas. Ainda, "[...] este foco da permacultura em aprender com culturas indígenas é baseado na evidência de que essas culturas têm existido em relativo equilíbrio com seu ambiente e sobrevivido por mais tempo do que qualquer um dos nossos recentes experimentos de civilização" (HOLMGREN, p. 1, 2002, tradução nossa). Esses princípios são o (1) Cuidado com a Terra, o (2) Cuidado com as Pessoas e a (3) Partilha justa.

3. Método de Design: baseado no pensamento sistêmico, o design em permacultura nos auxilia no como fazer o planejamento consciente de um assentamento humano sustentável, apresentando princípios e passos que norteiam esse processo. Além de conceitos de caráter técnico (como análise de elementos, planejamento por zonas, setorização e localização relativa), a permacultura oferece princípios originários de uma maneira de perceber o mundo, como os 12 princípios de design elaborados por Holmgren (2012) e outros/as autores/as.

Uma de suas características distintivas, quando comparada a outros movimentos que têm como ponto de partida a agricultura, é sua forma de difusão. No fim da década de 1980, Bill Mollison sistematizou o currículo de um curso inicial de formação em permacultura, intitulado Permaculture Design Course (PDC) ou Curso de Design em Permacultura, em português.

Scott Pittman (PITTMAN, 2014), um dos pioneiros nos trabalhos em permacultura, retrata que um PDC é a porta de entrada para compreendermos o design em permacultura. Nesse sentido, a conclusão de um PDC permite o reconhecimento desse/a estudante como um/a aprendiz em permacultura, e espera-se que ele/a continue seu processo de aprendizagem atuando de forma prática em todas as categorias que são abordadas no curso. Maringoni, Timmerman e Pamplona (2018, p. 3-4) trazem que o PDC é:

[...] um curso imaginado e montado por Bill Mollison para formar um permacultor. O curso é baseado no livro clássico Permaculture Designers' Manual (Manual dos Designers em Permacultura) [...]. Permacultura é uma ciência complexa e não uma técnica ou um conceito vago. Também não se restringe a uma área do conhecimento ou especialidade. Assim, para iniciar o planejamento de espaços permaculturais é essencial ter essa base ampla. Mollison elenca os conteúdos e uma carga horária mínima de 72 horas, além da obrigatoriedade de se elaborar o design como atividade de conclusão de curso. Também estipula a obrigatoriedade de $100 \%$ de presença para que se receba ao certificado. 
A permacultura chega ao Brasil num momento de intenso debate das pautas ambientais, como a Conferência das Nações Unidas para o Meio Ambiente em 1992 (Rio-92). Isso explica por que em 1992 aconteceu o I PDC no Brasil, em Viamão/RS, ministrado por Bill Mollison e Scott Pittman (FERREIRA NETO, 2018).

Atualmente, em todo o mundo, diversas organizações têm debatido o currículo, a carga horária e os métodos de ensino dos PDCs. No Brasil, um histórico de conflitos interpessoais e a ausência de um fórum nacional representativo têm enfraquecido discussões mais aprofundadas sobre PDCs, o que não significa que grupos locais, regionais ou no ambiente universitário tenham abandonado esse trabalho ou a organização dos cursos. Pelo contrário, a oferta da PDCs no Brasil tem se descentralizado e popularizado, tornando a permacultura acessível a pessoas de baixa renda, ainda que de forma tímida (FERREIRA NETO, 2018).

Dado esse panorama, este trabalho, recorte de uma pesquisa de doutorado (FOSSALUZA, 2019), busca contribuir para as discussões acerca do ensino de permacultura no Brasil, tendo como recorte os Cursos de Design em Permacultura (PDCs). Assim, os objetivos deste trabalho são (1) mapear e caracterizar os Cursos de Design em Permacultura (PDC) existentes no Brasil e (2) analisar os PDCs no Brasil quanto aos valores de inscrição, ao perfil dos/as educadores/as (classes sociais, raças/etnias e gêneros), e aos objetivos dos cursos, aprofundando o debate acerca de sua qualidade.

\section{Material e Métodos}

Neste trabalho, temos como base uma perspectiva crítica de educação. Consequentemente, as concepções de educação ambiental e de permacultura também derivam dessa forma de se ver e entender o mundo.

Assim, como exposto por Saviani (2012, p. 13), entendemos o trabalho educativo como "[...] o ato de produzir, direta e intencionalmente, em cada indivíduo singular, a humanidade que é produzida histórica e coletivamente pelo conjunto dos homens", num processo que o autor se fundamenta na ideia de criação de uma segunda natureza. Paulo Freire (FREIRE, 1996, 2019), outra referência essencial da educação crítica, ajuda-nos a entender que a educação, como experiência especificamente humana, aparece como forma de intervenção no mundo. Como atividade não neutra e praticada por seres humanos que sofrem condicionantes biológicos, culturais, sociais, políticos e históricos, a educação pode nos capacitar a investigar, a desvendar e a compreender as contradições da sociedade na perspectiva de sua transformação.

Nesse sentido, nosso estudo busca trabalhar com as condições históricas determinantes da vida dos sujeitos na sociedade capitalista, isto é, considerando-se a formação econômica desta sociedade (TOZONI-REIS, 2007), tendo a teoria marxista como principal base para a coleta e análise dos dados. Isso não significa que nossas análises excluirão outros determinantes que influenciam nossas vidas, sejam eles de ordem cultural, biológica, política, religiosa e outras, mas que seguirá um referencial teórico claro e definido.

Entendemos que uma abordagem qualitativa é mais interessante e completa para a compreensão das relações entre seres humanos e desses com a natureza, superando-se, assim, a lógica formal cartesiana (MINAYO et al., 1998). Por outro lado, por trazermos um componente de mapeamento e um volume grande de dados, também recorreremos ao conjunto de informações e análises quantitativas, que são essenciais 
para a compreensão do fenômeno estudado de forma mais ampla. Isso significa dizer que este estudo tem como referência a pesquisa qualitativa, mas não exclui os dados quantitativos nessa interpretação da realidade, já que não se configura como um estudo apenas descritivo da realidade empírica, mas essencialmente interpretativo, isto é, tratamos os dados em busca de dar uma interpretação crítica à realidade empírica.

Apesar da nossa vontade de discutir muitas frentes de educação em permacultura, foi necessário fazer um recorte. Por isso, focamo-nos em ações de ensino de permacultura por meio dos PDCs, ou seja, como conhecimentos, valores, hábitos, símbolos e conceitos são compartilhados nesses cursos, entendendo que ele é um espaço inicial de formação nesse tema, sistematizado e o mais comumente procurado pelas pessoas que se interessam pela área.

Temporalmente, coletamos dados referentes a cursos oferecidos entre 2013 a 2017, período escolhido pela maior possibilidade de encontrarmos informações confiáveis em plataformas digitais e de contarmos com educadores/as que ainda atuam em PDCs.

Resumidamente, nosso universo de pesquisa é formado pelos PDCs no Brasil oferecidos entre 2013 e 2017. Como sujeitos de pesquisa desse universo, optamos pelas pessoas que atuam como educadores/as nesses cursos.

As ferramentas para coleta de dados são apresentadas no Quadro 1. O projeto de pesquisa foi submetido à análise do Comitê de Ética da Faculdade de Ciências da Universidade Estadual Paulista (UNESP) e cadastrado na Plataforma Brasil, recebendo parecer favorável à sua realização (Número do Parecer: 2.224.439). Todas as pessoas participantes foram informadas desse procedimento, esclarecidas quanto à natureza da pesquisa e consentiram em fornecer informações ao pesquisador, com a leitura e assinatura de um Termo de Consentimento Livre e Esclarecido.

Quadro 1 - Objetivos do trabalho e métodos de coleta de dados

\begin{tabular}{|l|l|l|}
\hline & \multicolumn{1}{|c|}{ Objetivo } & \multicolumn{1}{|c|}{ Ferramentas de coleta de dados } \\
\hline 1 & $\begin{array}{l}\text { Identificar e caracterizar os coletivos e educadores/as que oferecem Cursos } \\
\text { de Design em Permacultura no Brasil }\end{array}$ & Revisão bibliográfica, análise documental e questionário \\
\hline 2 & $\begin{array}{l}\text { Analisar os Cursos de Design em Permacultura no Brasil quanto aos valores } \\
\text { de inscrição, público-alvo e objetivos }\end{array}$ & Análise documental e questionário \\
\hline
\end{tabular}

Fonte: elaborado pelos autores.

Para o trabalho de mapeamento, realizamos uma ampla revisão bibliográfica. A única iniciativa identificada nesse sentido é a pesquisa de mestrado de Ferreira Neto (2017), que resultou na publicação de um livro (FERREIRA NETO, 2018). Esse estudo, porém, não teve como objeto exclusivo de estudo o ensino de permacultura.

Além da revisão, nosso mapeamento quantitativo contou com uma busca ativa em bases de dados já existentes e em páginas eletrônicas de institutos e coletivos que trabalham com permacultura.

Atualmente, não há uma instituição, rede ou base de dados que agregue todas as atividades desenvolvidas em permacultura no Brasil, apesar de algumas iniciativas terem se destacado nos últimos anos, como a Rede Permacultura Social Brasileira, a Rede Permear de Permacultores e o Projeto Común Tierra. Utilizamos as informações disponíveis nesses bancos de dados como ponto de partida, assim como uma rede de dados mundial sobre permacultura, chamada Permaculture Global. 
Após o mapeamento, passamos à coleta de dados junto aos/às educadores/as. A determinação das amostras das populações analisadas sofreu variações ao longo da pesquisa, pois certa flexibilidade já é esperada em projetos de pesquisa qualitativa (PIRES, 2008): inicialmente, esperávamos realizar um estudo censitário, contatando todas as pessoas que atuam na facilitação desses cursos, mas essa opção se mostrou inviável temporalmente durante o processo de pesquisa, especialmente devido ao grande número de educadores/as de PDCs e dificuldades em contatá-los/as. Ainda assim, obtivemos uma amostra abrangente e diversa desta população.

É importante ressaltar uma opção metodológica inicial que fizemos na determinação da população de estudo. Devido à expansão de iniciativas de permacultura, principalmente a partir de 2008 (FERREIRA NETO, 2018) e à existência de PDCs compostos por membros de distintos coletivos, optamos por enviar, individualmente, questionários a cada educador/a, não apenas a uma pessoa representante do grupo. Entendemos, também, que essa opção nos permite analisar o ensino de permacultura no Brasil de forma mais aprofundada e condizente com a realidade.

A análise qualitativa dos dados partiu do estudo documental de informações das páginas eletrônicas dos grupos e de respostas dadas aos questionários pelos/as educadores/ as de PDCs no Brasil. Os questionários foram aplicados à distância, por meio de uma plataforma on-line, ou presencialmente, quando possível. Tomamos o cuidado, antes da divulgação e contato com os/as educadores/as, de aplicarmos um questionário-piloto com pessoas que já atuaram como educadoras em PDCs ou desenvolveram trabalhos com ensino de permacultura. A seguir, começamos a ampla divulgação do questionário por meio de redes sociais, e-mails, telefonemas e conversas. As respostas foram coletadas no período de maio de 2017 a junho de 2018.

Além de algumas informações necessárias para a caracterização dos/as educadores/ as de PDCs no Brasil, fizemos perguntas fechadas (nas quais eram apresentadas opções de respostas) e abertas (com espaço livre para respostas discursivas das pessoas participantes) mais aprofundadas.

Para a análise dos dados, assumimos a proposta metodológica de superar as observações empíricas da realidade, o senso comum educacional, com o propósito de apreendermos a realidade concreta por meio da reflexão teórica (SAVIANI, 1991). Nesse sentido, tomamos como referencial o método materialista histórico-dialético e a Pedagogia Histórico-Crítica (PHC), além de outras propostas críticas da educação que, em algumas situações, pareceram-nos mais apropriadas que a PHC, especialmente para ações educativas fora do ambiente escolar.

No contexto deste estudo, buscamos superar as desavenças pessoais e entre os grupos, tentando desvelar questões mais profundas e relativas às contradições presentes na sociedade capitalista e como elas influenciam a ação educativa em permacultura - e viceversa. Além disso, com base no método materialista histórico-dialético, essa interpretação exige tomada de posição pela transformação dessa sociedade contraditória, o que perpassa nossas análises.

Ao pensarmos o fenômeno educacional em si e, considerando-se a necessidade de conhecermos os diversos elementos das práticas educativas para interpretarmos a realidade ambiental e educacional da permacultura a partir do método materialista histórico-dialético (TOZONI-REIS, 2008), vemos que tanto a permacultura quanto a educação ambiental 
permitem que a relação entre ser humano e natureza seja uma possibilidade de se configurar como categoria simples de análise. Ou seja, essa relação sujeito-objeto é o elemento central da análise: "[...] compreender a relação sujeito-objeto é compreender como o ser humano se relaciona com as coisas, com a natureza, com a vida" (PIRES, 1997, p. 84).

Por outro lado, entendemos que este estudo tem como recorte o ensino de permacultura, e não necessariamente as manifestações materiais e não materiais no ambiente das pessoas que atuam em permacultura. Isso significa que nossa categoria simples de análise é a educação, entendendo que aprendemos, ao longo das nossas vidas, formas de nos relacionarmos com o ambiente, em sociedade (TOZONI-REIS, 2008). Em suma, o questionamento de como se dá o processo educativo na permacultura é o norte deste estudo.

Interessa-nos discutir se as ações educacionais desenvolvidas em permacultura tendem a contribuir para um processo de humanização das pessoas que participam dos PDCs ou para um processo de alienação, no sentido de reproduzir as relações de exploração e de dominação inerentes ao modo capitalista de produção.

\section{Resultados e Discussão}

Nesta seção, apresentamos o mapeamento e caracterização dos PDCs realizados no Brasil e as características relevantes desses cursos, trilhando um caminho para discutir suas implicações para o ensino de permacultura.

\section{Mapeamento dos PDCs realizados no Brasil}

Para determinarmos que tipo de curso foi considerado um PDC, partimos de critérios historicamente utilizados no Brasil:

1. Ele deve ter, no mínimo, uma carga horária de 72 horas;

2. Os conteúdos devem ter como base aqueles determinados por documentos elaborados nas décadas de 1980 e 1990 por Bill Mollison e outras pessoas pioneiras no ensino de permacultura, especialmente o Permaculture Design Course Outline (MOLLISON; SLAY; JEEVES, 1985) ou Manual do curso de design em permacultura 1 . Apesar de existirem propostas curriculares diferentes noutros países (BELL, 2010; FRANCIS, 2008; MORROW, 2014; BRITAIN PERMACULTURE ASSOCIATION, 2018), todas derivam do currículo originalmente elaborado por Bill Mollison; e,

3. Os cursos devem contemplar um trabalho de design como atividade de conclusão desse curso (MARINGONI; TIMMERMANN; PAMPLONA, 2018).

Com isso em mente, apresentamos, abaixo, os 38 grupos que ofereceram PDCs no Brasil no período de estudo (Quadro 2).

Além disso, os dados nos indicam muitas parcerias entre coletivos, o que permitiu a realização de PDCs em várias localidades, muitas vezes diferentes da própria sede do grupo.

A pesquisa também identificou $\mathbf{2 1 0}$ pessoas que atuam como educadores/as nos PDCs no Brasil. Contamos com a colaboração de 102 delas, que responderam ao questionário de pesquisa (48,5\% do total), cujas respostas são utilizadas nas discussões a seguir.

\footnotetext{
'Este documento é também conhecido por permacultores(as) brasileiros(as) como Syllabus.
} 
Quadro 2 - Grupos ou coletivos que ofereceram PDCs no Brasil (2013-2017)

\begin{tabular}{|c|c|c|}
\hline & Grupo & Localidade de realização \\
\hline 1 & Ananda Kiirtana* & Belmiro Braga/MG \\
\hline 2 & $\begin{array}{l}\text { Associação de Resgate à Cidadania por Amor à Humanidade (ARCAH) / Parceria: Missão } \\
\text { CENA }\end{array}$ & Juquitiba/SP \\
\hline 3 & Coletivo PermaSampa / Parceria: Instituto Casa da Cidade e Sem Muros & São Paulo/SP \\
\hline 4 & Clã Pé Vermelho & Rolândia/PR \\
\hline 5 & Ecoetrix Parquescola* & São Thomé das Letras/MG e Varginha/MG \\
\hline 6 & Ecossítio Nova Terra Maquiné & Maquiné/RS \\
\hline 7 & Escola da Cidade & São Paulo/SP \\
\hline 8 & $\begin{array}{l}\text { Grupo Curare de Permacultura } \\
\text { Parcerias: Associação Veracidade, Casa Diart's, Pupa Permacultura e Sítio Beira Serra }\end{array}$ & $\begin{array}{l}\text { Botucatu/SP, São Carlos/SP e São José dos } \\
\text { Campos/SP }\end{array}$ \\
\hline 9 & $\begin{array}{l}\text { Instituto Arca Verde } \\
\text { Parcerias: Instituto Biorregional do Cerrado (IBC), Conselho de Assentamentos Sustentáveis } \\
\text { das Américas (CASA Brasil) e Cooperativa de Agricultores Familiares de São Francisco de } \\
\text { Paula (COOPAF Serrana) }\end{array}$ & São Francisco de Paula/RS \\
\hline 10 & Instituto Biorregional do Cerrado (IBC) & Alto Paraíso de Goiás/GO \\
\hline 11 & Instituto Çarakura, em parceria com Escola Velotropa & Florianópolis/SC \\
\hline 12 & $\begin{array}{l}\text { Instituto de Pesquisas e Criação Taipal (IPC Taipal) } \\
\text { Parcerias: Sol Soluções Holísticas e Cura Gastronômica }\end{array}$ & Piedade/SP \\
\hline 13 & Instituto Nhandecy & Curitiba/PR \\
\hline 14 & Instituto de Permacultura: Organização, Ecovilas e Meio Ambiente (IPOEMA) & Brasília/DF \\
\hline 15 & Instituto de Permacultura da Bahia (IPB) & Vale do Capão/BA e Rio das Contas/BA \\
\hline 16 & Instituto de Permacultura e Ecovilas da Mata Atlântica (IPEMA) & Ubatuba/SP \\
\hline 17 & Instituto de Permacultura do Ceará (IPC) & Eusébio/CE \\
\hline 18 & Instituto de Permacultura e Ecovilas do Cerrado (IPEC) & Pirenópolis/GO \\
\hline 19 & $\begin{array}{l}\text { Instituto de Permacultura e Ecovilas dos Pampas (IPEP) e Rama Permacultura } \\
\text { Parcerias: Hotel Fazenda e Escola de Permacultura Fazenda da Serra }\end{array}$ & Itatiaia/RJ, Barra do Garças/MT e Bagé/RS \\
\hline 20 & Instituto Ná Lu'um Latinoamerica, em parceria com Cidade Escola Ayni & Guaporé/RS \\
\hline 21 & Instituto Pindorama & Nova Friburgo/RJ \\
\hline 22 & Instituto de Permacultura Cerrado-Pantanal e Instituto Ambiental Quinta do Sol & Taboco/MS e Corguinho/MS \\
\hline 23 & Marizá Epicentro & Tucano/BA \\
\hline 24 & Morada da Floresta & São Paulo/SP \\
\hline 25 & Morada Ekoa & Imbituba/SC \\
\hline 26 & Morada Natural Bioarquitetura e Permacultura & Conceição do Rio Verde/MG \\
\hline 27 & $\begin{array}{l}\text { Nova Oikos / Parcerias: Coletivo BioWit, IPEPA, Wake Up Colab, Instituto Ideal do Paraná, } \\
\text { Instituto Ná Lu'um, Marcos Ninguém Permacultura, Sítio Pico do Beija Flor, Permacultura } \\
\text { Social Brasileira (PSB) e Alianza Permaneser }\end{array}$ & $\begin{array}{l}\text { Curitiba/PR, Viamão/RS, Florianópolis/SC, } \\
\text { Alpestre/RS e Balneário Camboriú/SC }\end{array}$ \\
\hline 28 & Novo Portal da Chapada* & Alto Paraíso de Goiás/GO \\
\hline 29 & Sete Ecos & Sete Lagoas/MG \\
\hline 30 & Sítio Olho D'Água & Mogi das Cruzes/SP \\
\hline 31 & Sítio Nós na Teia, em parceria com Toca da Coruja & Brasília/DF \\
\hline 32 & Sítio Nova Canaã & Olinda/PE \\
\hline 33 & Universidade Federal de Santa Catarina (NEPerma - UFSC) & Florianópolis/SC \\
\hline 34 & Universidade Federal do Cariri (UFCA) & Juazeiro do Norte/CE \\
\hline 35 & Universidade Federal de Viçosa (UFV) & Viçosa/MG \\
\hline 36 & $\begin{array}{l}\text { UniPermacultura } \\
\text { Parcerias: Eco Aldeia Flecha da Mata e Reserva do Ser }\end{array}$ & $\begin{array}{l}\text { Alpestre/RS, Aracati/CE, Chapecó/SC, Rio de } \\
\text { Janeiro/RJ e à distância }\end{array}$ \\
\hline 37 & Vila Gerais* & Piatã/BA \\
\hline 38 & Yvy-Porã Estação de Permacultura & São Pedro de Alcântara/SC \\
\hline
\end{tabular}

Nota: $\mathrm{o}$ asterisco $\left({ }^{*}\right)$ indica que os cursos organizados por esses coletivos se caracterizam pela vinda de um grupo de educadores/as responsáveis por ministrar as aulas do PDC, que não necessariamente fazem parte do coletivo que recebeu o curso.

Fonte: elaborado pelos autores. 
Nossos dados também nos permitem analisar a distribuição geográfica dos PDCs no território brasileiro. A partir da investigação, organizamos os dados de forma a evidenciar a quantidade de localidades que receberam um PDC durante o período de estudo. Encontramos que, apesar de 38 grupos serem responsáveis por esses cursos no Brasil, eles foram oferecidos em, pelo menos, 44 localidades diferentes (Figura 1). Isso nos mostra que, apesar da atuação na sua localidade-sede, muitos grupos atuam noutras localidades a convite de parceiros.

Apesar da abundante oferta de PDCs no Brasil, sua distribuição geográfica no território nacional não é uniforme: a região Norte brasileira, por exemplo, não recebeu nenhum desses cursos durante todo o período estudado.

A maior oferta de cursos tem acontecido na região Sudeste, em 16 territórios diferentes no período - São Paulo é o Estado com a maior quantidade de localidades que receberam PDC. O único Estado da região que não recebeu PDCs no período foi o Espírito Santo.

A região Sul vem logo a seguir, com 13 localidades recebendo PDCs no período do estudo, com destaque para os Estados do Rio Grande do Sul e Santa Catarina, áreas com uma tradição mais longa no oferecimento desses cursos. As regiões Nordeste (com 8 localidades) e Centro-Oeste (com 6 localidades) são aquelas com menor oferta de cursos no período. Cabe ressaltar, porém, a atuação histórica do IPEC, em Pirenópolis/GO e do Sítio Nós na Teia, em Brasília/DF, que apesar de não terem atuado em outros municípios da região, vêm oferecendo PDCs continuamente há mais de 10 anos.

É importante ressaltar, ainda, que a inexistência de PDCs numa região não indica a ausência de ações educativas em permacultura, já que muitas outras ações desse cunho são observadas.

Figura 1 - Localidades que receberam PDCs entre 2013 e 2017

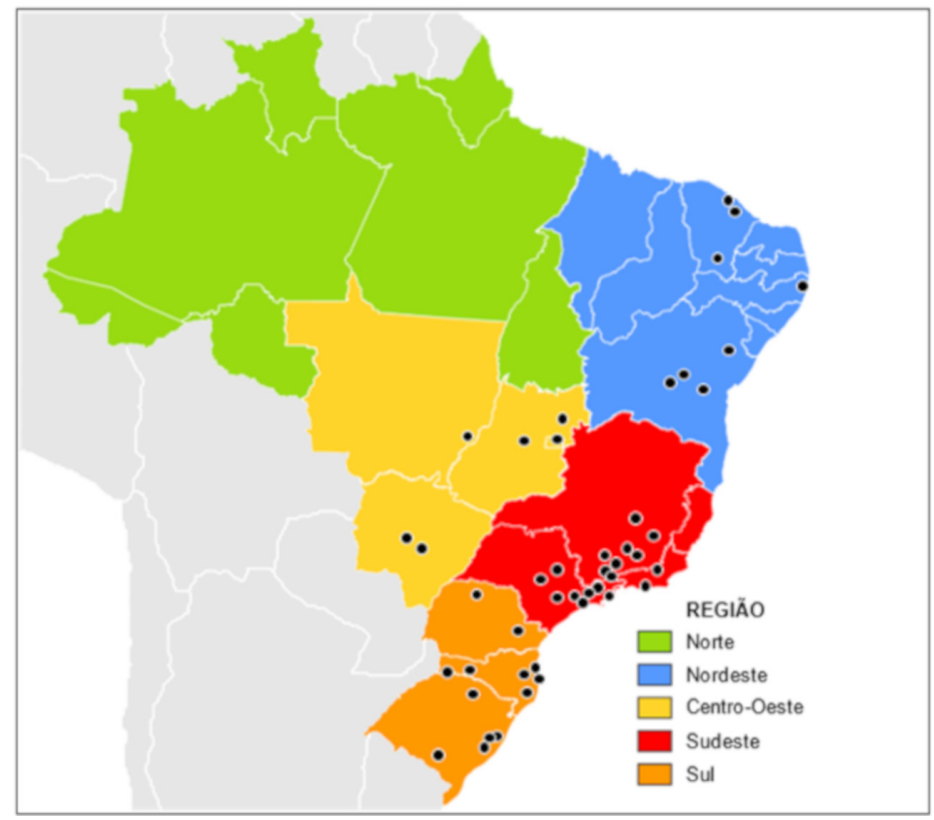

Fonte: adaptada de: https://commons.wikimedia.org/w/index.php?curid=2231836. Acesso em: 11 set. 2018.

\section{Os custos para participar de um PDC e seu público: em busca da popularização}

O valor de inscrição nos PDCs é comumente apontado como um dos fatores predominantes para o perfil elitista da permacultura, especialmente nas suas duas primeiras décadas no Brasil. 
Os dados coletados (Figura 2) mostram que 57,8\% dos PDCs oferecidos no Brasil possuem valor de inscrição de 1 a 2 salários mínimos. Por outro lado, 34,2\% dos PDCs possuem um valor de inscrição menor do que um salário mínimo, sendo que 10,5\% deles são gratuitos. Numa direção contrária, 7,9\% dos cursos apresentam valor de inscrição maior do que 2 salários mínimos (o maior valor cobrado por um PDC no Brasil, no período estudado, foi $\mathrm{R} \$ 3.500,00)$. Se considerarmos o rendimento médio mensal da população brasileira (aproximadamente 2 salários mínimos), podemos equivocadamente concluir que os valores cobrados nos PDCs são condizentes com a realidade dos/as trabalhadores/as.

Figura 2 - Valor médio de inscrição nos PDCs oferecidos no Brasil entre 2013 e 2017

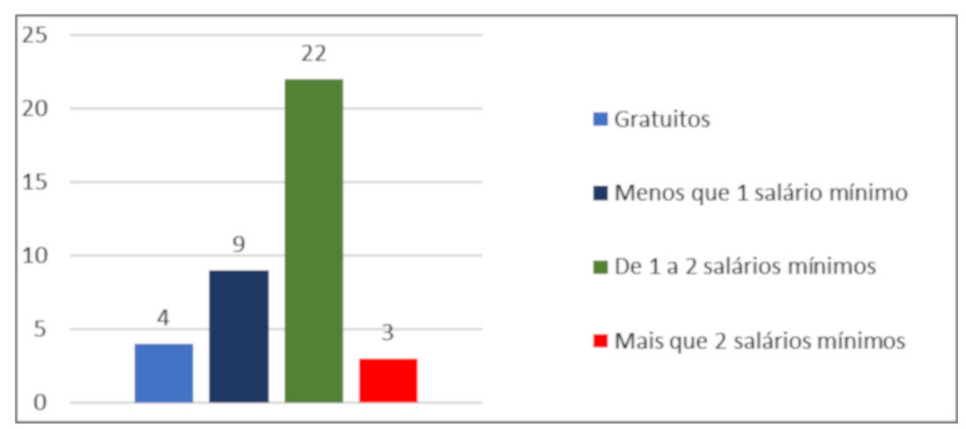

Fonte: elaborado pelos autores.

O que podemos afirmar, com absoluta certeza, é que os valores de inscrição são muito altos quando tomamos como base o rendimento médio mensal per capita domiciliar dos $50 \%$ mais pobres da população brasileira - em 2017, esse valor correspondia a $\mathrm{R} \$ 754,00$, menos que um salário mínimo (INSTITUTO BRASILEIRO DE GEOGRAFIA E ESTATÍSTICA, 2018) -, e que uma pessoa não pode utilizar todo seu rendimento mensal para financiar um curso.

Além dos custos, o perfil do público que participa dos PDCs sempre gera questionamentos sobre o caráter elitista da permacultura. Se, historicamente, o curso era frequentado por pessoas de classe média ou alta, a diminuição dos valores de inscrição tem permitido a inserção de pessoas da classe trabalhadora; se havia predominância de homens, o acolhimento à diversidade presente nos grupos tem possibilitado um menor desequilíbrio quanto ao gênero e permitido a participação de famílias inteiras, inclusive de crianças.

Diante desses dados, podemos dizer que a abordagem holística e transdisciplinar da permacultura tem atraído pessoas com diferentes formações, que a veem como uma possibilidade de melhorar sua prática profissional e sua vida pessoal; agricultores/as, quilombolas/as, pessoas participantes de movimentos sociais de acesso à terra na zona rural e à moradia no ambiente urbano, moradores/as de regiões periféricas das grandes cidades e indígenas também começam a participar mais dos PDCs.

Ressaltamos que outras iniciativas de caráter popular têm ocorrido, como PDCs em parceria com movimentos sociais, sindicatos rurais e poder público, assim como outras ações para além dos PDCs. Mas, concordamos com Ferreira Neto (2018), ao analisarmos que esse movimento de popularização se fortaleceu a partir de 2008 de forma descentralizada e sem um diálogo estabelecido entre os diversos coletivos atuantes. 
Apesar de todos os avanços na popularização da permacultura no Brasil, não podemos deixar de considerar que ainda existem muitos obstáculos que impedem a participação de pessoas negras e indígenas; apesar do crescimento da participação de mulheres, elas ainda são minoria na composição do público de estudantes e, especialmente, de educadores/as; pessoas com nível mais baixo de escolaridade formal também têm sua inserção dificultada, seja pela linguagem científica rebuscada que pode ser de difícil compreensão ou por elas não se sentirem parte do público desses cursos devido a diversas questões, que podem ser desde a estética, a formação de outros/as participantes, o formato e os valores dos cursos, o desconhecimento do termo Permacultura etc.

\section{O que se espera de um PDC: objetivos dos cursos}

Tendo em vista o limitado acúmulo de discussões, a nível nacional, sobre o desenvolvimento dos PDCs no Brasil, buscamos descobrir qual a percepção dos/as educadores/as atuantes quanto aos objetivos desses cursos. Ao entendermos que a educação nunca é neutra, e sim um processo diretivo e intencional, os objetivos que temos para determinada prática educativa são fundamentais para o modo como essa ação se dará na realidade concreta; essa, por sua vez, influencia a nossa própria teorização, num ciclo contínuo de práxis (FREIRE, 1996).

A maior parte das respostas apresenta que os PDCs têm como objetivo "instrumentalizar ou fornecer uma base conceitual ou teórica introdutória à Permacultura ou promover uma formação inicial". Além disso, destaca-se também o agrupamento "sensibilizar, conscientizar ou promover a reflexão sobre as relações entre ser humano e o ambiente" e "capacitar ou internalizar o método de design em Permacultura ou o planejamento sustentável de uma área". Para além dessas, diversas outras respostas foram dadas, evidenciando uma ausência de consenso, por parte dos/as educadores/as, em relação aos objetivos de um PDC. A falta de clareza e de responsabilidade no oferecimento desses cursos foi um dos temas recorrentes num documento elaborado por aprendizes em permacultura (APRENDIZES..., 2017), que possui duras críticas à permacultura e ao seu ensino.

Por isso, consideramos importante, com esses dados colocados, discutir quais desses objetivos podem ser considerados nucleares aos PDCs e quais deles se apresentam como secundários.

Tendo como base Saviani (2012), propomos aqui compreender com clareza qual a razão de ser dos PDCs, ou seja, quais objetivos são nucleares e trazem identidade a esse curso, lembrando que partimos de uma perspectiva crítica ou progressista da prática docente de educadoras ou educadores (FREIRE, 1996). Devido a esses referenciais teóricos, precisamos estar alertas a propostas que veem que os PDCs têm como objetivo "repassar ou transmitir um conjunto de técnicas ou soluções práticas", seja por evidenciar uma concepção "bancária" da educação (FREIRE, 2019) ou por reduzir a permacultura a um conjunto de técnicas, desconsiderando todo seu arcabouço ético e filosófico.

Outros itens mencionados pelos/as educadores/as se assemelham às bases que fundamentam um PDC, e não aos objetivos do curso. A segunda opção mais mencionada, "sensibilizar, conscientizar ou promover a reflexão sobre as relações entre ser humano e o ambiente" mostra uma aproximação com a educação ambiental, mas não, necessariamente, 
em suas vertentes críticas. Apesar de considerarmos que a relação entre ser humano e ambiente transpassa todo o currículo desenvolvido no PDC, ela não se configura como um objetivo nuclear do curso.

Sob esse ponto de vista e, a partir das respostas fornecidas pelos/as educadores/as, tentamos agregar esses objetivos numa síntese, entendendo que o objetivo nuclear dos PDCs é "propiciar formação inicial teórica e prática à Permacultura, com foco na Metodologia de Design e sua intrínseca relação com a ética e filosofia da Permacultura, favorecendo uma transformação da realidade e a crescente autonomia das pessoas participantes".

Essa síntese busca trazer clareza aos propósitos de um PDC, enfatizando sua importância na superação de uma visão tecnicista da permacultura, sua especificidade como um curso focado na metodologia de design (mas que não se sustenta sem a fundamentação éticofilosófica da permacultura) e que tem firme intenção de contribuir com a transformação da realidade concreta ao fomentar a autonomia das pessoas participantes.

Como objetivos secundários desses cursos, defendemos que eles contribuem para a criação de redes de cooperação entre permacultores/as e para sua difusão e popularização. Permeiam e sustentam esses objetivos a educação ambiental, no sentido de sensibilizar, conscientizar ou promover a reflexão sobre as relações entre a humanidade e o ambiente, além de trazer uma visão ampla, sistêmica e complexa da realidade, assim como a valorização de saberes tradicionais e a da educação pelo exemplo, destacando ações concretas realizadas pelos/as próprios/as educadores/as ou por outras pessoas que trabalham com permacultura.

\section{Um breve perfil dos/as educadores/as dos PDC no Brasil}

Nesta seção discutiremos o perfil dos/as educadores/as de PDCs no Brasil quanto à renda (classe social), gênero e raça, entendendo que é impossível discutir sociedade no Brasil sem considerar a interseccionalidade desses conceitos, como defendido por Davis (2018).

No nosso estudo, encontramos que $\mathbf{4 5 , 1 9 \%}$ dos/as educadores/as possuem renda mensal média per capita de 1 a 3 salários mínimos. Se considerarmos as pessoas que dizem receber menos do que um salário mínimo por mês, temos que a maioria das pessoas que atuam com ensino de Permacultura em PDCs faz parte das classes sociais D e E.

Com relação ao gênero, dois terços dos/as educadores/as são do sexo masculino, ou seja, os PDCs ainda são prioritariamente mediados por homens.

Quanto à raça ou etnia, observamos que 71\% dos/as educadores/as se autodenominam brancos/as; pardos/as correspondem a $14 \%$ das pessoas, enquanto pessoas que se denominam amarelas constituem aproximadamente $5 \%$ do total. Por fim, somente $2 \%$ dos/ as educadores/as atuantes nos PDCs se autodenominam pretos/as, e nenhuma pessoa se autodeclara indígena.

Esses dados nos permitem dizer que a maior parte dos educadores/as de PDC no Brasil são homens, brancos e das classes média-baixa ou baixa.

Se, por um lado, esses dados contradizem uma percepção generalizada sobre o perfil elitista dos/as permacultores/as, por outro, eles indicam que a permacultura ainda é um território pouco diverso quanto à raça/etnia e centrado em figuras masculinas, apesar do crescente número de ações que buscam superar essa condição. 
Nesse sentido, considerando a necessidade de uma análise interseccional entre raça, classe, gênero e sexualidade (DAVIS, 2018) - ainda que esta última não tenha sido analisada neste estudo -, o ensino de permacultura, e a permacultura em si, apresenta-se distante de movimentos com caráter popular, crítico e revolucionário, ainda que avanços tenham acontecido desde sua incorporação às pautas socioambientais no Brasil.

\section{Síntese: os PDCs no ensino de permacultura no Brasil}

Inicialmente, é essencial reforçar que não há, até o momento, qualquer forma de organização representativa, a nível nacional, que estabeleça parâmetros ou diretrizes para a realização dos PDCs no país. Existem, porém, redes de diálogo entre permacultores/as a nível estadual ou regional, além de uma rede universitária de núcleos de permacultura.

Também, não localizamos encontros, simpósios ou congressos que discutam os PDCs e a permacultura no Brasil (ao contrário do movimento agroecológico, por exemplo), fazendo com que os PDCs no Brasil caminhem numa dita lógica de "autorregulação"mercadológica: a qualidade desses cursos seria avaliada pelos/as participantes e educadores/as, sendo que aqueles considerados melhores continuaram a existir em detrimento aos PDCs com qualidade menor, como uma imensa rede de retroalimentação. Ainda que essa análise dialogue com princípios da própria permacultura, ela não representa o panorama que encontramos, com cursos que, apesar de possuírem o mesmo nome, possuem objetivos e custos diferentes, cada qual com seus "nichos de mercado".

Quantitativamente, a pesquisa encontrou 38 grupos que ofereceram PDCs no período de 2013 a 2017, com um total de $\mathbf{2 1 0}$ educadores/as atuantes em PDCs - desses/ as, participaram da nossa pesquisa 102 pessoas - distribuídos em todas as regiões do país, com exceção da Norte.

A análise qualitativa permite afirmar que a busca por um perfil único desses cursos e da ação pedagógica dos/as educadores/as se mostraria um exercício que converteria uma realidade complexa numa apreensão simplista e limitada, como também seria buscar traçar um único perfil para as distintas correntes em educação ambiental. Ainda, avaliamos que não há consenso e clareza entre os/as educadores/as de PDCs no Brasil sobre uma série de questões nucleares sobre esses cursos, em especial nas bases teóricas utilizadas para a elaboração do currículo e seus objetivos, além da falta de diálogo entre os/as educadores/ as de diferentes cursos.

Apesar de termos observado, nos últimos anos, um movimento para a popularização da permacultura, como apontado por Ferreira Neto (2018), e diversas manifestações de repúdio a ações de cunho preconceituoso e discriminatório de qualquer natureza, nossos dados nos mostram que o ensino de permacultura ainda é predominantemente conduzido, nos PDCs, por homens brancos, ainda que partes da classe trabalhadora. Além disso, os valores cobrados para as inscrições são altos quando comparados à renda da população brasileira, impedindo a acesso da população trabalhadora.

Entendemos que o ensino de permacultura se configura como um campo de disputa, com ações de caráter contraditório e heterogêneo. Se, por um lado, apresenta bases teóricometodológicas que buscam a superação do modo capitalista de produção, por outro, muitas vezes, não se configura como um movimento social coerente com suas bases, caraterística 
observada nos altos custos de inscrição nos PDCs; na menor participação das mulheres, de pessoas negras e indígenas enquanto educadoras; na inexistência de uma organização nacional representativa, que discuta e elabore princípios para uma proposta pedagógica nesses cursos. Dialeticamente, o ensino de permacultura no Brasil também se caracteriza por ações que buscam eliminar a restrição imposta pelos custos dos cursos, permitindo a crescente participação de pessoas da classe trabalhadora, fomentando a inserção de mulheres, de pessoas negras e indígenas, além de ativamente buscar a inclusão de grupos marginalizados, como movimentos sociais rurais e urbanos, comunidades tradicionais e quilombolas. Também, movimentos a nível local, regional ou no ambiente universitário têm servido para a construção de novas redes de discussão, algumas das quais não foram incluídas neste trabalho por não trabalharem especificamente com PDCs.

A análise dos dados apresentados neste trabalho nos leva a concluir que o ensino de permacultura no Brasil é bastante contraditório, assim como a própria sociedade na qual está inserida.

Entendemos que o campo de estudo e de discussão em permacultura é bastante jovem e - por isso ou não - possui uma série de questões que podem ser trabalhadas na perspectiva de seu amadurecimento e de elevação da qualidade. A educação ambiental crítica, nesse sentido, como campo de estudo e de ação historicamente mais desenvolvido e coerente, pode contribuir para trazer mais clareza e coerência ao ensino de permacultura no Brasil, superando concepções de caráter conservador e que tenham como objetivos centrais a alteração de comportamentos individuais e a busca por autonomia particular.

\section{Agradecimentos}

Agradecemos ao Conselho Nacional de Desenvolvimento Científico e Tecnológico (CNPq) pela concessão da bolsa de estudos (Processo: 163751/2015-3) que permitiu o desenvolvimento da pesquisa, assim como à Faculdade de Ciências da UNESP, à Universidade de Santiago de Compostela, campus de Lugo, e ao SESC Jundiaí. Ainda, agradecemos às contribuições de todas as pessoas que atuam no ensino de permacultura, especialmente aos/às amigos/as do Grupo Curare de Permacultura.

\section{Referências}

APRENDIZES de permacultura: manifesto coletivo. [2017]. Disponível em: https://www.facebook. com/Aprendizes-de-Permacultura-528583294007800. Acesso em: 14 set. 2018.

BELL, G. Permaculture design course handbook. Berwickshire: [s.n.], 2010. Disponível em: https:// permateachers.eu/wp-content/uploads/2014/05/PERMACULTURE-DESIGN-COURSE-HandbookNovember-2013.pdf. Acesso em: 2 set. 2020.

BRITAIN PERMACULTURE ASSOCIATION. Permaculture design course: core curriculum v 2.3. [2018]. Disponível em: https://www.permaculture.org.uk/education/pdc-core-curriculum. Acesso em: 2 set. 2020.

DAVIS, A. A liberdade é uma luta constante. São Paulo: Boitempo, 2018.

FERGUSON, R. S.; LOVELL, S. T. Permaculture for agroecology: design, movement, practice, and worldview: a review. Agronomy for Sustainable Development, Switzerland, v. 34, n. 2, p. 251-274, 2014. 
FERREIRA NETO, D. N. Uma alternativa para a sociedade: caminhos e perspectivas da permacultura no Brasil. São Carlos: Edição do autor, 2018.

FERREIRA NETO, D. N. Caminhos e perspectivas para a popularização da permacultura no Brasil. 2017. 368 f. Dissertação (Mestrado em Ciências) - Escola Superior de Agricultura Luiz de Queiroz, Universidade de São Paulo, Piracicaba, 2017.

FOSSALUZA, A. S. Ensino e formação em permacultura no Brasil: uma análise crítica a partir dos Cursos de Design em Permacultura (PDCs) e da Educação Ambiental. 2019. 393 p. Tese (Doutorado em Educação para a Ciência) - Faculdade de Ciências, Universidade Estadual Paulista, Bauru, 2019. Disponível em: http://hdl.handle.net/11449/190999. Acesso em: 27 ago. 2020.

FRANCIS, R. Permaculture design course handbook. Nimbin, Australia: Djanbung Gardens Permaculture Education Centre, [2008].

FREIRE, P. Pedagogia da autonomia: saberes necessários à prática educativa. 25. ed. São Paulo: Paz e Terra, 1996.

FREIRE, P. Pedagogia do oprimido. 68. ed. Rio de Janeiro: Paz e Terra, 2019.

HOLMGREN, D. Os fundamentos da permacultura: um resumo dos conceitos e princípios apresentados no livro 'Princípios e caminhos da permacultura além da sustentabilidade', de autoria de David Holmgren. [s. I.]: Holmgren Design, 2012.

HOLMGREN, D. Permaculture: principles and pathways beyond sustainability. Victoria: Holmgren Design Services, 2002.

INSTITUTO BRASILEIRO DE GEOGRAFIA E ESTATÍSTICA. Rendimento de todas as fontes 2017: PNAD contínua. Rio de Janeiro: IBGE, 2018. Disponível em: https://biblioteca.ibge.gov.br/visualizacao/ livros/liv101559_informativo.pdf. Acesso em: 2 set. 2020.

LAYRARGUES, P. P.; LIMA, G. F. C. As macrotendências político-pedagógicas da educação ambiental brasileira. Ambiente \& Sociedade, São Paulo, v. 17, n. 1, p. 23-40, 2014.

MARINGONI, S.; TIMMERMANN, J.; PAMPLONA, S. B. P. Bases para um curso de design em permacultura (PDC): permacultores pioneiros do Brasil. [2018]. Disponível em: https://yvypora.files.wordpress. com/2018/03/bases-para-um-curso-de-design-em-permacultura.pdf. Acesso em: 2 set. 2020.

MINAYO, M. C. S.; DESLANDES, S. F.; CRUZ NETO, O.; GOMES. R. Pesquisa social: teoria, método e criatividade. 14. ed. Petrópolis: Vozes, 1998.

MOLLISON, B.; SLAY, R. M.; JEEVES, A. Permaculture design course outline. Santa Fé, EUA: Permaculture Institute, 1985.

MOLLISON, B. Permaculture: a designers' manual. 2. ed. Sister Creek: Tagari Publications, 2009.

MORROW, R. Earth user's guide to teaching permaculture. 2. ed. Hampshire: Permanent Publications, 2014.

PIRES, A. Amostragem e pesquisa qualitativa: ensaio teórico e metodológico. In: POUPART, J. et al. A pesquisa qualitativa: enfoques epistemológicos e metodológicos. Petrópolis: Vozes, 2008. p. 154211.

PIRES, M. F. C. O materialismo histórico-dialético e a educação. Interface, Botucatu, v. 1, n. 1, p. 8394, 1997. DOI: http://dx.doi.org/10.1590/S1414-32831997000200006.

PITTMAN, S. Definition of PDC standard. [2014]. Disponível em: http://lists.ibiblio.org/pipermail/ permaculture/. Acesso em: 11 ago. 2019. 
RIBEIRO, D. S.; TIEPOLO, E. V.; VARGAS, M. C.; SILVA, N. R. (org.). Agroecologia na educação básica: questões propositivas de conteúdo e metodologia. 2. ed. São Paulo: Expressão Popular, 2017.

SAUVÉ, L. Currents in environmental education: mapping a complex and evolving pedagogical field. Canadian Journal of Environmental Education, Thunder Bay, v. 10, n. 1, p. 11-37, 2005.

SAVIANI, D. Educação: do senso comum à consciência filosófica. 10. ed. São Paulo: Cortez, 1991.

SAVIANI, D. Pedagogia histórico-crítica: primeiras aproximações. 11. ed. rev. Campinas: Autores Associados, 2012.

SCHILLING-TREIN, E. A educação ambiental crítica: crítica de quê? Revista Contemporânea de Educação, Rio de Janeiro, v. 7, n. 14, p. 295-308, 2012. Disponível em: https://revistas.ufrj.br/index. php/rce/article/view/1673. Acesso em: 10 set. 2020.

TOZONI-REIS, M. F. C. Educação ambiental: natureza, razão e história. 2. ed. rev. Campinas: Autores Associados, 2008.

TOZONI-REIS, M. F. C. A pesquisa-ação-participativa e a educação ambiental: uma parceria construída pela identificação teórica e metodológica. In: TOZONI-REIS, M. F. C. A pesquisa-açãoparticipativa em educação ambiental: reflexões teóricas. Botucatu: Fundibio, 2007. p. 121-161.

TRATADO de educação ambiental para sociedades sustentáveis e responsabilidade global. In: BRASIL. Ministério do Meio Ambiente. Educação ambiental: por um Brasil sustentável: ProNEA, marcos legais \& normativos. Brasília: MME, 2014. p. 85-90.

VENKAT. New agriculture: a permaculture point of view. 2. ed. Azamabad: Charita Impressions, 2017. 